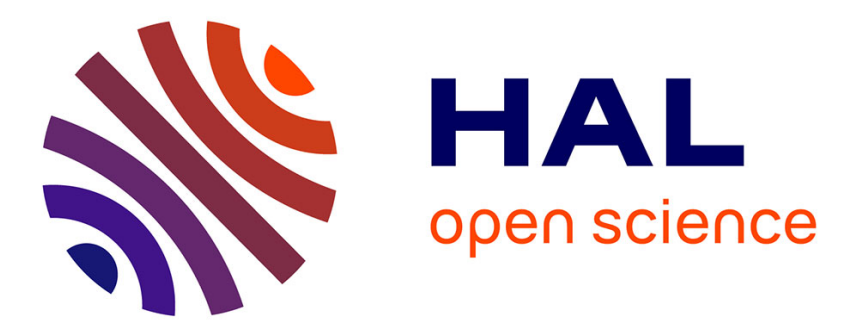

\title{
Collaborative Network for District Energy Operation and Semantic Technologies: A Case Study
}

Corentin Kuster, Jean-Laurent Hippolyte, Yacine Rezgui

\section{To cite this version:}

Corentin Kuster, Jean-Laurent Hippolyte, Yacine Rezgui. Collaborative Network for District Energy Operation and Semantic Technologies: A Case Study. 19th Working Conference on Virtual Enterprises (PRO-VE), Sep 2018, Cardiff, United Kingdom. pp.486-495, 10.1007/978-3-319-99127-6_42 . hal02191160

\section{HAL Id: hal-02191160 \\ https://hal.inria.fr/hal-02191160}

Submitted on 24 Jul 2019

HAL is a multi-disciplinary open access archive for the deposit and dissemination of scientific research documents, whether they are published or not. The documents may come from teaching and research institutions in France or abroad, or from public or private research centers.
L'archive ouverte pluridisciplinaire HAL, est destinée au dépôt et à la diffusion de documents scientifiques de niveau recherche, publiés ou non, émanant des établissements d'enseignement et de recherche français ou étrangers, des laboratoires publics ou privés. 


\title{
Collaborative Network for District Energy Operation and Semantic Technologies: A Case Study
}

\author{
Corentin Kuster, Jean-Laurent Hippolyte, Yacine Rezgui \\ BRE Trust Centre for Sustainable Engineering, Cardiff University, Cardiff CF24 3AB, \\ United Kingdom; http://www.cardiff.ac.uk/bre-trust-centre-sustainable-engineering. \\ E-mail : kusterc@,cardiff.ac.uk;
}

\begin{abstract}
The growing interest toward renewable energies and alternative energy sources has led to the development of an increasingly complex district energy landscape with multiple agents and systems. In this new prospect, some frameworks such as USEF [1] or holonic multi-agent systems [2] propose new approaches, where, in the way of a Virtual Organisation Breeding Environment (VOBE) [3], diverse organizations cooperate on a long-term basis to run an energy system. This study focuses on the THERMOSS project, an EU-funded project that investigates the efficient operation of district heating and cooling networks, and demonstrates that such organisation can be integrated into the Collaborative Networks (CNs) paradigm. Additionally, a semantic approach is briefly introduced as a mean to support and improve data transfer and communication between the different entities of THERMOSS as a $\mathrm{CN}$.
\end{abstract}

Keywords: Collaborative Networks, District Heating and Cooling, Semantic.

\section{Introduction}

Energy systems are changing with the current drive to reduce carbon emission from fossil fuelled energy sources. Indeed, energy planning is moving from centralized infrastructures to distributed systems where multiple renewable sources are integrated [1]. In this prospect, district heating systems are on the rise and a new management paradigm is emerging where network flexibility is key [4]. Demand-side management and demand-response approaches are deployed to fulfil multi-objective optimisation on energy cost, peak demand shaving, supply-demand matching and promote the use of renewable energy sources[4]. Such an approach relies on high-quality and extensive data, often in real or near-real time, placing data and information exchange at the core of the system[1]. The field is indeed moving toward a holistic and ICT (Information and communications technology) driven management of interdisciplinary and multiagent systems and falls within the smart city movement[5]. Various parties pursuing a common purpose and leveraging a cyber-physical infrastructure make energy planning a form of collaborative network [3] $(\mathrm{CN})$. Within a $\mathrm{CN}$, autonomous, geographically distributed, and heterogeneous entities join complementary sets of skills in order to achieve a common goal that would be difficult or costly with an individual approach [3]. Consequently, information exchange and interoperability between $\mathrm{CN}$ parties and 
software are prerequisites of an efficient implementation [2]. Some argue that heterogeneous data and communication protocols can be supported by semantic models [2], [5], [6] This paper presents the THERMOSS project as a collaborative network for smart district heating and cooling and introduces a semantic-driven approach for flexibility management of district heating and cooling. In a first part, the collaborative networks principles will be exposed and the new energy system paradigm will be described. THERMOSS will then be introduced and compared against collaborative networks theory. Ontology based systems are believed to be useful for the creation of a workable knowledge base for CNs [7]. Therefore, the ongoing efforts for the development of ontological data modelling are presented in a second part. Interoperability challenges will be introduced along with the ontologies considered to solve the issue within THERMOSS. Finally, the article will conclude on the benefits of such an approach as well as the future intended work in THERMOSS for its implementation.

\section{Energy System as a Collaborative Network}

In terms of organisation, certain complex systems would benefit from the added value of diverse entities that are not hold under the same well defined structure. This type of organisational structure has been theorised and formalised in the early 2000 by Camarinha-Matos and Afsarmanesh [8] as Collaborative Networks (CNs). Collaborative Networks are defined as a

"variety of entities (e.g., organizations and people) that are largely autonomous, geographically distributed, and heterogeneous in terms of their: operating environment, culture, social capital, and goals that collaborate to better achieve common or compatible goals, and whose interactions are supported by computer network" [3].

The collaboration can take different forms depending on the duration, purposes, type of product and entities involved. Branches of CNs include[8]: virtual enterprise that is an alliance of enterprises formed to answer a business opportunity and communicate over computer network; virtual organisation that is in principle similar to virtual enterprises with the inclusion of non-profit organisation; virtual organisation breeding environment that is a virtual organisation relying on a "base" long-term cooperation agreement and interoperable infrastructure; e-science that coordinates resource-sharing and collaboration over a body of science; and a virtual laboratory that is a subset of escience where the different research centres work together to solve a particular problem.

In a context where production is increasingly efficient and competitive, CNs are believed to achieve concurrency in operations, improve the workforce performance, effectively disseminate domain knowledge, reduce environmental impact, fast respond to needs and opportunities and be more innovative [7], [9]. Moreover, the growth in information and communication technologies (ICTs) supports the implementation of $\mathrm{CNs}$ by enabling distributed and heterogeneous systems and agents to share and communicate seamlessly [10]. CNs have already been considered in various areas such as: 
- manufacturing for adaptive and responsive production [11];

- construction to better manage and coordinate large projects [12];

- energy provider for flexible and sustainable energy provision [13], [14].

The latter is particularly interesting in the current climate within the energy domain. Indeed, the energy system paradigm is changing due to the integration of distributed energy resources. It is moving from a centralized scheme where energy suppliers ensure the provision of energy from their own power plants to their end users, toward a distributed, bidirectional energy generation and distribution [1]. This new paradigm includes key aspects such as the integration of renewables, demand response, flexibility to reduce peak loads, system reliability, user becoming prosumers [15] etc. New stakeholder roles have appeared such as:

- suppliers, balance responsible parties and producers that need to ensure demand response and flexibility;

- distribution network operators and distribution system operators that must maintain network stability over peak loads and provide insightful information via the integration of smart meters;

- $\quad$ transmission system operators that must ensure energy flow balance against intermittent energy sources;

- prosumers that are partly producer and consumer and fully aware of the market and environmental concerns;

- $\quad$ aggregators and energy service companies that cumulate resource flexibility for a more reliable market and provide various energy related services such as maintenance or information services [1].

In this new prospect, initiatives have already been developed for the creation of distributed energy resources and its optimisation. An analogue situation can be observed in the heating and cooling sector where smart thermal grids are increasingly considered. This approach includes large scale and distributed renewable sources with well insulated distribution network, low temperature heat carrier and intelligent control and metering along with storage units that ensure cost effective and environmentally friendly energy supply [16]. THERMOSS is a European funded project that implements such innovative energy solutions for district heating and cooling (DHC) along with two decision support tools for a successful integration and optimisation: a sizing toolbox to facilitate DHC technology selection and integration; and an optimisation platform to control distributed energy resources and match need with demand. This study will focus on the latter. 

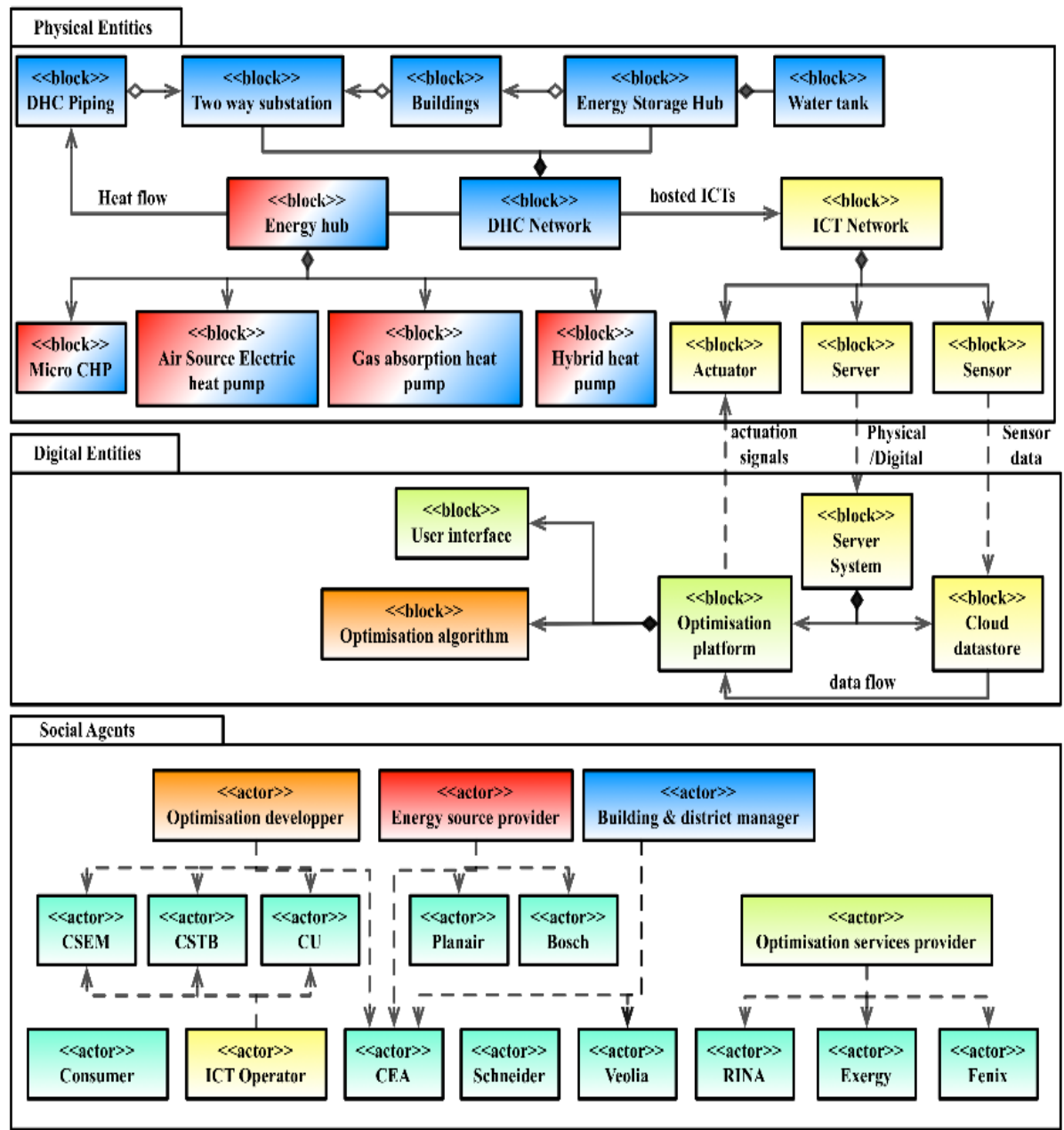

Figure 1 THERMOSS SysML structure diagram: physical, digital entities and social entities.

Figure 1 shows THERMOSS structure diagram with a focus on the optimisation process. The different actors of the project are presented in the Social Agents group where their main contribution are allocated, namely optimisation developer, energy source provider, building and district manager and optimisation services provider. A colour code associates those contributions to physical and digital entities within the project. Additionally, the diagram presents the relationships between entities. 


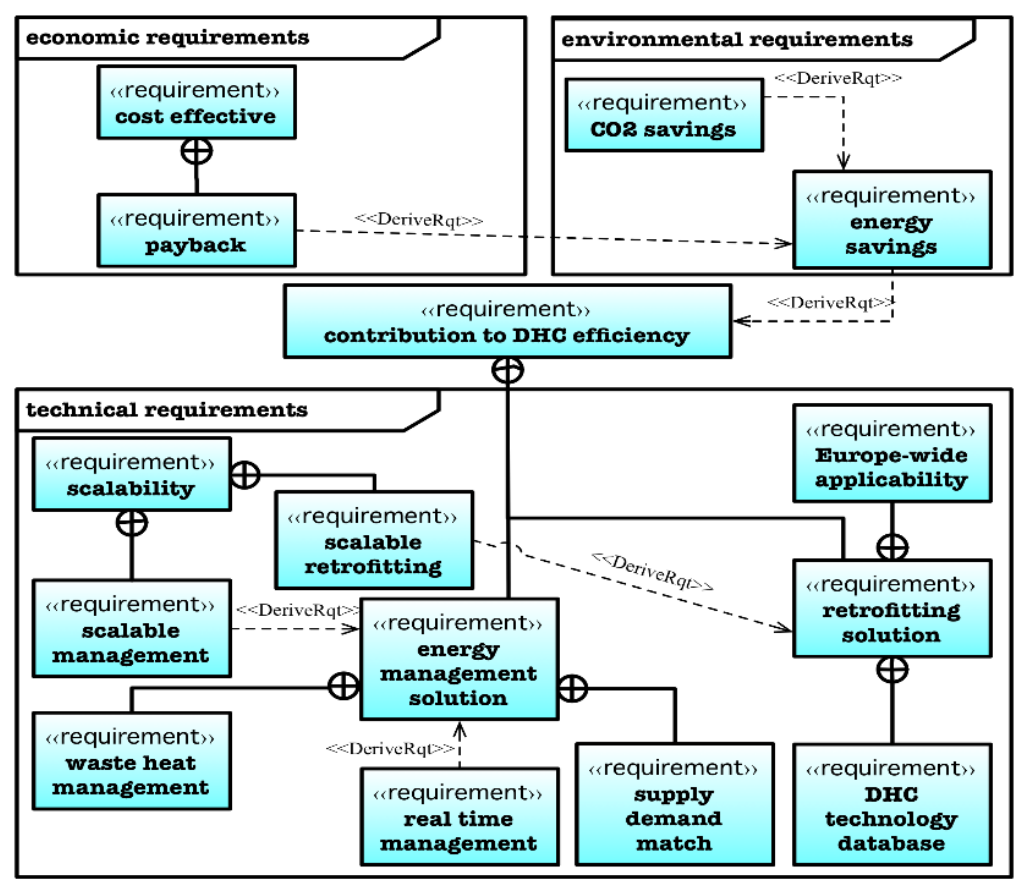

Figure 2 THERMOSS SysML requirement diagram

Figure 2 shows the requirements that the project must fulfil collaboratively. This diagram formalized the economic, environmental and technical requirements that the project must fulfil and how they are linked together. According to the diagrams, on many aspects the THERMOSS project can be assimilated to a $\mathrm{CN}$. Indeed, various entities are working together on the operation of a system that combines multiple domains for the completion of environmental, economic and technical objectives. Entities and requirements interconnections demonstrate the system dependencies and introduced a need for a collaborative approach. Table 1 refers to the 2016's CamarinhaMatos article [17] and shows how the THERMOSS project covers most aspects of a "collaborative smart grid".

A preliminary study is currently ongoing for the creation of a semantic repository of the different sites components. This semantic model will support ontology-based data access [18], i.e the access and transmission of time-dependent sensor/actuator data to the fault detection module and the district heating and cooling optimisation modules, using semantic queries (SPARQL). Those two modules being managed by independent actors, this common model will help in a seamless communication. For example, the optimisation module can avoid the integration of faulty data by accessing output data shared by the fault detection module over the semantic repository. 
Table 1 CN within THERMOSS (Sources for collaboration forms [17])

\begin{tabular}{|c|c|c|c|c|}
\hline Catergories & Collaboration forms & Motivation & $\begin{array}{l}\text { THERMOS } \\
\text { S coverage }\end{array}$ & THERMOSS element \\
\hline $\begin{array}{l}\text { Value added } \\
\text { services }\end{array}$ & $\begin{array}{l}\text { Virtual organizations } \\
\text { for service provision } \\
\text { or long-term strategic } \\
\text { networks/VO } \\
\text { breeding } \\
\text { environments }\end{array}$ & $\begin{array}{l}\text { Providing services for energy } \\
\text { cost and emissions reduction. }\end{array}$ & $\checkmark$ & $\begin{array}{l}\text { Optimisation services via } \\
\text { the provision of } \\
\text { optimisation platform and } \\
\text { its algorithms }\end{array}$ \\
\hline Energy market & $\begin{array}{l}\text { Collaborative } \\
\text { coalitions or virtual } \\
\text { power plants }\end{array}$ & $\begin{array}{l}\text { Smoothing peak demand via } \\
\text { monetary incentives }\end{array}$ & & \\
\hline $\begin{array}{l}\text { Customer } \\
\text { engagement and } \\
\text { behaviour } \\
\text { change }\end{array}$ & $\begin{array}{l}\text { Consortia of } \\
\text { customers often } \\
\text { relying on existing } \\
\text { social network }\end{array}$ & $\begin{array}{l}\text { Raising consumer awareness } \\
\text { toward energy problematics to } \\
\text { facilitate peak shaving }\end{array}$ & & \\
\hline $\begin{array}{l}\text { Social smart } \\
\text { grid }\end{array}$ & $\begin{array}{l}\text { Dynamic consortia of } \\
\text { consumers (a kind of } \\
\text { collaborative cyber- } \\
\text { physical system) }\end{array}$ & $\begin{array}{l}\text { Dynamic monitoring for } \\
\text { effective demand response } \\
\text { and cost reduction }\end{array}$ & $\checkmark$ & $\begin{array}{l}\text { Implementation of smart } \\
\text { sensors that indirectly } \\
\text { represent consumers. }\end{array}$ \\
\hline $\begin{array}{l}\text { Energy } \\
\text { management }\end{array}$ & $\begin{array}{l}\text { Goal oriented } \\
\text { consortia }\end{array}$ & $\begin{array}{l}\text { Optimisation of energy } \\
\text { demand-response and peak } \\
\text { shaving. }\end{array}$ & $\checkmark$ & $\begin{array}{l}\text { Demand-Response and } \\
\text { peak shaving optimisation } \\
\text { with } \\
\text { advanced control } \\
\text { techniques for storing heat } \\
\text { in the network. }\end{array}$ \\
\hline Infrastructure & $\begin{array}{l}\text { Long-term networks } \\
\text { of (smart) cyber- } \\
\text { physical components, } \\
\text { with self-organizing } \\
\text { capabilities }\end{array}$ & $\begin{array}{l}\text { Maintain and operate resilient, } \\
\text { safe, and self-healing } \\
\text { infrastructures }\end{array}$ & $\checkmark$ & $\begin{array}{l}\text { Energy sources providers, } \\
\text { district \& building } \\
\text { managers and ICTs } \\
\text { operators jointly work on } \\
\text { the implementation and } \\
\text { maintenance of the } \\
\text { infrastructures. }\end{array}$ \\
\hline $\begin{array}{l}\text { Policy and } \\
\text { roadmaps }\end{array}$ & $\begin{array}{l}\text { Long-term strategic } \\
\text { networks and goal- } \\
\text { oriented virtual } \\
\text { organizations }\end{array}$ & $\begin{array}{l}\text { Ease collaboration between } \\
\text { industry involved in energy } \\
\text { infrastructure among them } \\
\text { as well as customer. }\end{array}$ & & \\
\hline
\end{tabular}

\section{Semantics for Interoperability within THERMOSS}

Interoperability is pivotal for collaborative networks, at a superstructural level, to homogenise information flows between heterogeneous organisations [19], but also, at an infrastructural level, to benefit from new cloud-based services [20]. More specifically, unifying semantic understanding throughout a collaborative network is key to overcome conceptual barriers, not only at the ICT level [10], but also at a higher level of abstraction [21], [22].

Ontologies are instrumental not only in:

- consolidating inter-enterprise knowledge [11];

- driving the design of services in lign with the Service Oriented Architecture paradigm [10]

- $\quad$ overarching heterogeneous data structures [23];

- but also, as exemplified in this paper, reconciling the semantics of multiple operational support tools (e.g. simulations, optimisation algorithms). 
A key outcome of THERMOSS is the development of an optimisation platform and control system to balance energy supply within the heating network. The optimisation relies on data acquisition from sensors and control over actuators. There is therefore a need for the semantic representation of sensors and their readings as well as the different entities involved in data exchange and actuators. THERMOSS is currently investigating two ontologies as potential semantic basis:

- W3C Semantic Sensor Network (SSN) an OWL 2 ontology that defines capabilities and properties of sensors, their readings and the sensing process [24]. Based on the Dolce Ultra-Lite ontology (DUL), an upper level ontology, SSN and its core ontology SOSA (Sensor, Observation, Sample, and Actuator) are an extended version of the Observations \& Measurements ontology [25] including sensors and their relationships. Physical sensors can be represented as Sensing Device that makes some Observation. An Observation is then link to an Observed Property (e.g. temperature) and a Feature of interest (e.g. air in the room 237). The output and its value are then represented by the Sensor Output and Observation Value classes. Additional classes allow the description of sensors networks (e.g. parent/child sensor relationships) and sensing processes (e.g. calculation method). Finally, even though locations, units, sensor hierarchy types were not included, they can be easily integrated via cross ontology object/data properties [26]. Several projects are currently using the ontology for application specific purposes [27]-[29].

- Smart Appliances Reference Ontology (SAREF) developed for semantic representation of smart appliances, including extensions for building and energy appliances. In SAREF, devices have a central role, being defined as "tangible object designed to accomplish a particular task in households, common public buildings or offices. In order to accomplish this task, the device performs one or more functions"[30]. Therefore, a temperature sensor is a device that is defined by its function "sensing" of "temperature" (saref:SensorType). Additionally, the device is related to a room or space (saref:BuildingSpace). Finally, profiles are associated to devices and can be used for the optimisation of some properties such as energy for instance.

SAREF and SSN/SOSA differ in philosophy. While SSN remains abstract and can potentially describe any type of observation, SAREF is more industry oriented with concrete devices that serve well defined purposes. Semantic overlaps exist between the two ontologies such as saref:Sensor and saref:Meter are subclasses sosa:Sensor, saref:Actuator and saref:Switch are subclasses of sosa:Actuator or that saref:BuildingSpace can be seen as a subclass of sosa:Platform etc. 


\section{Conclusion and Future Work}

Changing energy systems require changing organisational structures. Collaborative networks are believed to help in the establishment of virtual organisations in the energy sector where numerous entities from different domains collaborate to achieve a common goal. The EU funded THERMOSS project takes part in on-going efforts for the integration and management of renewable district heating and cooling heat sources. Focusing on the optimisation process within the project and supported by the literature, this paper has considered THERMOSS from the viewpoint of collaborative networks. Consequently, a key pre-requisite for THERMOSS as a collaborative network for energy balance optimisation is an efficient information exchange across domain and organisations. In this prospect, a semantic approach is considered with the use of a common ontology. Two ontologies have been addressed, the Semantic Sensor Network (SOSA/SSN) and the Smart Appliances Reference Ontology (SAREF) that have distinct approaches on the semantic representation of sensor networks within an urban environment and their readings. Future work would require the participation of the different partners of the project in a consultation through interviews and questionnaire. This iterative and participative process would then constitute a knowledge base across domains with relevant terminologies and identifies the overlaps with the existing ontologies. A more detailed methodology can be found in [5].

Acknowledgements. The research presented in this paper is financially supported by the Building Research Establishment (BRE) and the European Commission as part of the Horizon2020 THERMOSS (project Id: 723562).

\section{References}

[1] USEF Foundation, "USEF: the Framework specifications 2015," 2015.

[2] S. Howell, Y. Rezgui, J. L. Hippolyte, B. Jayan, and H. Li, "Towards the next generation of smart grids: Semantic and holonic multi-agent management of distributed energy resources," Renew. Sustain. Energy Rev., vol. 77, no. November 2015, pp. 193-214, 2017.

[3] L. M. Camarinha-Matos and H. Afsarmanesh, "Collaborative networks: a new scientific discipline," J. Intell. Manuf., vol. 16, no. 4-5, pp. 439-452, Oct. 2005.

[4] N. Blaauwbroek, P. H. Nguyen, M. J. Konsman, H. Shi, R. I. G. Kamphuis, and W. L. Kling, "Decentralized Resource Allocation and Load Scheduling for Multicommodity Smart Energy Systems,” IEEE Trans. Sustain. Energy, vol. 6, no. 4, pp. 1506-1514, 2015.

[5] J.-L. Hippolyte, Y. Rezgui, H. Li, B. Jayan, and S. Howell, "Ontology-driven development of web services to support district energy applications," Autom. Constr., 2017.

[6] M. Anda, F. Le Gay Brereton, J. Brennan, and E. Paskett, Smart Metering Infrastructure for Residential Water Efficiency: Results of a Trial in a Behavioural Change Program in Perth, Western Australia. 2013.

[7] L. M. Camarinha-Matos, H. Afsarmanesh, N. Galeano, and A. Molina, "Collaborative networked organizations - Concepts and practice in manufacturing enterprises," Comput. Ind. Eng., vol. 57, no. 1, pp. 46-60, Aug. 2009.

[8] L. M. Camarinha-Matos and H. Afsarmanesh, Collaborative Networked Organizations. 
Boston, MA: Springer US, 2004.

[9] National Research Council, "National Research Council. (1998). Visionary Manufacturing Challenges for 2020, Visionary manufacturing challenges for 2020/Committee on Visionary Manufacturing Challenges, Board on Manufacturing and Engineering Design, Commission on Engineering and Techn," in Board on manufacturing and engineering design commission on engineering and technical systems, 1998.

[10] R. J. . Rabelo, S. . Gusmeroli, C. . Arana, and T. . Nagellen, "The ecolead ICT infrastructure for collaborative networked organizations," IFIP Int. Fed. Inf. Process., vol. 224, no. 3, pp. 451-460, 2006.

[11] N. Silva and J. Rocha, "VE Infrastructures Requirements for Cooperation and Knowledge Sharing," in IFIP Int Federation for Information Processing, 2001, vol. 56, pp. 79-86.

[12] M. Keller, K. Menzel, and R. Scherer, "Towards a Meta-Model for Collaborative Construction Project Management," Collab. Networks Their Breed. Environ. SE - 38, vol. 186, pp. 361-368, 2005.

[13] L. Allan and K. Menzel, "Virtual Enterprises for Integrated Energy Service Provision," Leveraging Knowl. Innov. Collab. Networks, pp. 659-666, 2009.

[14] I. Praça, H. Morais, M. Cardoso, C. Ramos, and Z. Vale, "Virtual Power Producers Integration into Mascem," in Establishing the Foundation of Collaborative Networks, vol. 243, Boston, MA: Springer US, 2007, pp. 291-298.

[15] F. Rahimi and A. Ipakchi, "Demand response as a market resource under the smart grid paradigm," IEEE Trans. Smart Grid, vol. 1, no. 1, pp. 82-88, 2010.

[16] H. Lund, S. Werner, R. Wiltshire, S. Svendsen, J. E. Thorsen, F. Hvelplund, and B. V. Mathiesen, "4th Generation District Heating (4GDH). Integrating smart thermal grids into future sustainable energy systems.," Energy, vol. 68. pp. 1-11, Apr-2014.

[17] L. M. Camarinha-Matos, "Collaborative smart grids - A survey on trends," Renew. Sustain. Energy Rev., vol. 65, pp. 283-294, 2016.

[18] D. Calvanese and M. Giese10, "The Optique Project: Towards OBDA Systems for Industry (Short Paper)," OWL Exp. Dir. Work. OWLED, pp. 7-11, 2013.

[19] C. M. Chituc, C. Toscano, and A. L. Azevedo, "Towards seamless interoperability in collaborative networks," IFIP Int. Fed. Inf. Process., vol. 243, pp. 445-452, 2007.

[20] M. Petychakis, I. Alvertis, E. Biliri, R. Tsouroplis, F. Lampathaki, and D. Askounis, "Enterprise Collaboration Framework for Managing, Advancing and Unifying the Functionality of Multiple Cloud-Based Services with the Help of a Graph API," 2014, pp. $153-160$.

[21] W. Mulder, P. H. H. Rongen, and G. R. Meijer, "Towards ontology-based CNO matching applied to squads," Collab. Networks Their Breed. Environ., vol. 186, pp. 117-124, 2005.

[22] N. Daclin, D. Chen, and B. Vallespir, "Methodology for Enterprise Interoperability," IFAC Proc. Vol., vol. 41, no. 2, pp. 12873-12878, 2008.

[23] V. Guevara-Masis, H. Afsarmanesh, and L. O. Hertzberger, "Ontology-Based Automatic Data Structure Generation for Collaborative Networks," in PRO-VE 2004:Virtual Enterprises and Collaborative Networks, 2004, pp. 163-174.

[24] M. Compton, P. Barnaghi, L. Bermudez, R. García-Castro, O. Corcho, S. Cox, J. Graybeal, M. Hauswirth, C. Henson, A. Herzog, V. Huang, K. Janowicz, W. D. Kelsey, D. Le Phuoc, L. Lefort, M. Leggieri, H. Neuhaus, A. Nikolov, K. Page, A. Passant, A. Sheth, and K. Taylor, "The SSN ontology of the W3C semantic sensor network incubator group," J. Web Semant., vol. 17, pp. 25-32, 2012.

[25] S. J. D. Cox, "Ontology for observations and sampling features, with alignments to existing models," Semant. Web, vol. 8, no. 3, pp. 453-470, 2017. 
[26] W3C, "Semantic Sensor Network Ontology," 2005.

[27] E. Kharlamov, C. Svingos, D. Zheleznyakov, I. Horrocks, Y. Ioannidis, R. Moeller, S Brandt, E. Jimenez-Ruiz, Y. Kotidis, S. Lamparter, T. Mailis, C. Neuenstadt, Ö. Öezçep, and C. Pinkel, "Ontology-Based Integration of Streaming and Static Relational Data with Optique," in Proceedings of the 2016 International Conference on Management of Data SIGMOD '16, 2016, no. ii, pp. 2109-2112.

[28] I. P. Žarko, K. Pripužic, and M. Serrano, Interoperability and Open-Source Solutions for the Internet of Things, vol. 10218. 2017.

[29] G. Atemezing, O. Corcho, D. Garijo, J. Mora, M. Poveda-Villalón, P. Rozas, D. VilaSuero, and B. Villazón-Terrazas, "Transforming meteorological data into linked data," Semant. Web, vol. 4, no. 3, pp. 285-290, 2013.

[30] L. Daniele, F. den Hartog, and J. Roes, "Created in Close Interaction with the Industry: The Smart Appliances REFerence (SAREF) Ontology," in FOMI 2015. Lecture Notes in Business Information Processing, 2015, pp. 100-112. 